\title{
An integrated framework (CTSR-BWG) for outsourcing decisions in a marine manufacturing firm
}

\author{
Mohsen Cheshmberah $^{a^{*}}$, Reza Rahbin ${ }^{\mathrm{b}}$ and Maliheh Eftekhari ${ }^{\mathrm{a}}$
}

${ }^{a}$ Department of Industrial Engineering, Malek Ashtar University of Technology, Isfahan, Iran ${ }^{b}$ Department of Industrial Engineering, Amir Kabir University of Technology, Tehran, Iran

\begin{tabular}{|c|c|}
\hline CHRON I C L E & A B S T RACT \\
\hline $\begin{array}{l}\text { Article history: } \\
\text { Received June 29, } 2018 \\
\text { Accepted September } 302018 \\
\text { Available online } \\
\text { October } 62018 \\
\text { Keywords: } \\
\text { Outsourcing } \\
\text { Decision aiding } \\
\text { PROMETHEE } \\
\text { Marine }\end{array}$ & $\begin{array}{l}\text { One of the most important questions in outsourcing management is to decide on the allocation } \\
\text { of the activities, processes or services either from the inside or from the outside of the } \\
\text { organizations through outsourcing operations. It is necessary to determine the factors } \\
\text { influencing outsourcing decision making as well as their impacts on decisions. In this paper, } \\
\text { the existing approaches and models and their related criteria are studied and the necessary } \\
\text { criteria are explored based on different conditions in marine manufacturing industries. These } \\
\text { criteria are categorized in four dimensions; namely Capacity, Technology, Strategy and } \\
\text { financial, and Risk called CTSR. After determining the weights of the criteria based on paired- } \\
\text { wise comparisons, the related calculations are carried out using PROMETHEE method. } \\
\text { Finally, a Black, White, Gray (BWG) analysis is executed to determine whether a candidate } \\
\text { should be outsourced or not. }\end{array}$ \\
\hline
\end{tabular}

\section{Introduction}

During the past few decades, the traditional thinking in which the value chain activities took place inside of organizations has been replaced by an organized and integrated network in which fewer activities are accomplished done by the companies. On this basis, those activities that create value should only be made internally and the rest must be outsourced as much as possible (Georgantzas, 2001). Adam Smith believes that a family manager never makes anything at home that costs more than buying it (Bageri, 2008). Organizations are always looking for new strategies to develop their competitive advantage. outsourcing is one of these strategies that can lead to more organization competitiveness through reducing and controlling operating costs, focusing on core competencies, utilizing skilled professionals not available inside the organizations, improving quality, etc. (Bertolini, et al., 2004; Nayak, et al., 2007; Al-Kahtani, 2018). Understanding opportunities and challenges, and in other words, identifying and analyzing outsourcing risks (Hessami, 2018) and determining the effective criteria for outsourcing decision making are important, and lack of understanding can damage the organizations; In outsourcing literature, there are various risks such as disclosing key information

* Corresponding author

E-mail address: mcheshmberah66@gmail.com (M. Cheshmberah)

(C) 2019 by the authors; licensee Growing Science, Canada doi: $10.5267 /$ j.uscm.2018.10.003 
and strategic directions, disclosing research and development projects and new ideas, elimination of competitive advantage, etc. (Motadel, et al., 2011).

Understanding the advantages and disadvantages of outsourcing deepens our perception of the necessity of properly determining the criteria and making the right decision for outsourcing. These benefits include cost savings, reducing investment costs, increasing cash, converting fixed to variable costs, improving quality, increasing speed, increasing flexibility, access to the latest technology and infrastructure, access to skills and talents, increasing staffing activities, increasing focus on core competencies, assigning activities or processes that are difficult to manage, learning from competitors, resource release, responsiveness and better management, increasing transparency, risk sharing, etc. (Agrawal, et al., 2016; Nakhaee, et al., 2008).

Disadvantages and risks of outsourcing include hidden costs, reduced flexibility, poor contract or supplier selection, loss of knowledge and information and skills, loss of control, loss of core competencies, supplier dependency, loss of customers and opportunities, uncertainty, environmental change, damage to staff morale, conflict of interests, security implications, etc. (Bageri, 2008; Cheshmberah, et al., 2009). Obviously, in order to properly manage outsourcing in an organization, there is a need for a clear process, where one of the components of this outsourcing management process, is the important step of deciding outsourcing for each activity (Cheshmberah, et al., 2014). Outsourcing decisions at their higher levels should be considered strategic decisions so that these decisions would have a key impact on the survival and durability of an organization (especially startup companies) (Bustamante, 2018).

\section{Literature review}

Outsourcing decision-making in primary research is also referred to as "make or buy" decisions; in preliminary studies, outsourcing decisions were initially based on costs, the most famous example of which is Coase theorem (transaction cost economics); the matter for Coase theorem is that the use and benefit from the market may come along with waste of money. During a service or product purchasing, if the costs are too high, reliance on the inside of organization is more appropriate (Aubert, et al., 2004).

In Williamson's transaction cost theory (1975), transaction costs are the only outsourcing criterion (Cánez, et al., 2000; Miltenburg, 2003). Outsourcing decision-making can be based on important aspects such as "transaction cost theory" and "resource-based view" approach (Sharma, et al., 2015; Bustamante, 2018). Prahalad and Hamel (1990) argued the relationship between core competency and outsourcing. They considered core competency as collective learning in the organization, especially in how to coordinate different production skills and integrate multiple technology streams (Prahalad, et al., 1990). Venkatesan (1992) put forward an approach to the American Cummins Inc., and proposed the idea of link between product differentiation, family component analysis, and manufacturing capability as a way to make an outsourcing decision.

Welch and Nayak (1992) completed Venkatesan's work. Their framework improved the traditional cost analysis approach in terms of strategic and technological factors in the decision making process. In addition, factors such as the competitive advantage of process technology, process maturity and position of the competitors' process were taken into account in the final supply decision (Welch, et al., 1992). Probert (1996) tried to improve previous research by presenting a four-stage process to make or buy. The various stages in this methodology are initial business evaluation, internal-external analysis, strategic options assessment and optimal strategy selection. Probert used the strategic "make or buy" methodology for six (6) manufacturing businesses, and reported the effectiveness of this methodology.

Padillo and Daibi (1999) also looked at the outsourcing with a few criteria. They developed a sevenstep multi-criteria decision methodology for assessing make or buy strategies which included four factors of maximizing competitive strategic performance, minimizing risk, maximizing financial performance, maximizing management performance, simultaneously. In this model, various methods 
such as composite planning and analytical hierarchy process (AHP) (Saaty, 1987) were also used. Fill and Visser (2000) succeeded in proposing a combination of the outsourcing decision framework. They examined factors such as strategic factors, organizational structure and culture and cost (Fill, et al., 2000).

Tayles and Drury (2001) provided a model for supporting make-or-buy decision-making, relying on the strategic items and cost of investment. Fine et al. (2002) presented a model in which economic value added and strategic value added for the outsourcing decision were used. In the economic value added, factors such as costs, revenues, assets and the structure of competitive cost, and in strategic value added, customer importance, rate of technology change, competitive position of the company, capability of the supply base and product architecture were considered.

Ball (2003) presented a balanced decision matrix as a tool to assess the suitability of library services for outsourcing. In this matrix, the outsourcing decisions were evaluated based on factors such as cost of capital, number of suppliers, company strategies and service quality. Van Water and Van Peet (2006) presented an outsourcing decision-making model that has a more strategic focus and has a structure that allows the use of the AHP technique to reduce the complexity of the decision-making process.

Milecová et al. (2010) emphasized outsourcing decision-making to consider hidden costs. These costs include the cost of outsourcing monitoring, outsourcing management, current transaction cost in outsourcing (including contract costs, time costs, etc.) and costs related to return of investment. In addition to costs, it emphasizes internal capabilities. It also emphasizes the assessment of risk analysis and management. Cheshmberah et al. (2011a) considered the four dimensions of core competency, technology, information risk and economic dimension (total cost) in a study on a manufacturing company in aerospace industry. Cheng et al. (2012) used the Analytic Network Process (ANP) to create an outsourcing assessment framework and evaluated four dimensions (economic, political, technology, and vision of organization). Motadel et al. (2011) categorized main effective factors in outsourcing as strategic importance of the project (including the contribution of the project in achieving the organization's main goals, the amount of project benefit from the strategic resources of the organization, the degree of confidentiality of the project information, the importance of the project for the future of the organization), the project characteristics (including the level of project expertise, project complexity), the supplier characteristics (including customer confidence, technology ability, supplier's organizational capability, flexibility, time saving), the organizational characteristics (including employee expertise, financial ability, experience), and the cost (including the transaction cost, the cost of doing activity within the organization).

Cheshmberah et al. (2011) studied the impact of product life cycle on the importance of outsourcing decision-making criteria (Cheshmberah et al., 2011b). Attari et al. (2012) classified the criteria influencing outsourcing decision making to secondary criteria, control measures and their effective indicators, and presented a model based on the ANP (Niemira \& Saaty, 2004) and fuzzy DEMATEL techniques (Wu \& Lee, 2007) for outsourcing decision making in a car manufacturing company. The control criteria include quality, delivery, power, staff, cost of production and work processes, and secondary criteria include compliance with standards, average outsourcing replacement time, quality management system, timely delivery and other metrics. Tjader et al. (2014) presented a new approach based on the Balanced Scorecard (BSC) and the ANP process, based on customer, organizational learning and development and financial indicators and (internal) operations. These indicators include subsets based on the scorecard approach.

Modaka et al. (2018) used an integrated BSC and AHP fuzzy approach (Aikhuele \& Turan, 2017) for outsourcing decision making in Indian coal mines. Also, the same team in another paper used the combination of BSC and ANP to make outsourcing decisions in Indian coal mines (Modaka, et al., 2018). Various criteria mentioned in the subject matter have been used to develop a preliminary list of criteria on the case study. 


\section{Research methodology and data collection}

Firstly, in this paper, attempts have been made to classify the criteria used in the subject literature, and then, based on the research methodology, the criteria that are appropriate to the requirements of the case study are to be explored; Table 1 shows the criteria classification.

Table 1

Categorizing Effective Criteria for outsourcing Decision Making

\begin{tabular}{lllll}
\hline Internal capability & $\begin{array}{l}\text { Attributes of } \\
\text { activity/process/product }\end{array}$ & Cost & Supplier capability & $\begin{array}{l}\text { Strategy \& risk } \\
\text { management }\end{array}$ \\
\hline $\begin{array}{l}\text { sufficiency of internal } \\
\text { capacity }\end{array}$ & Product architecture & $\begin{array}{l}\text { outsourcing process } \\
\text { management costs }\end{array}$ & $\begin{array}{l}\text { Flexibility (volume, lot } \\
\text { size, technical, etc.) }\end{array}$ & $\begin{array}{l}\text { Information risk (strategic, } \\
\text { technical, security, etc.) }\end{array}$ \\
$\begin{array}{l}\text { organizational } \\
\text { Learning and growth }\end{array}$ & $\begin{array}{l}\text { Technical } \\
\text { Attractiveness }\end{array}$ & Cost saving(s) & Supply in crisis & $\begin{array}{l}\text { Protecting organization' } \\
\text { know how }\end{array}$ \\
$\begin{array}{l}\text { Internal technological } \\
\text { capability }\end{array}$ & Financial Attractiveness & & $\begin{array}{l}\text { sufficiency of supplier' } \\
\text { capacity }\end{array}$ & $\begin{array}{l}\text { Risks of employee } \\
\text { (motivation, focus, etc.) }\end{array}$ \\
$\begin{array}{l}\text { Deepening employees' } \\
\text { knowledge and skills }\end{array}$ & & & $\begin{array}{l}\text { Supplier' technological } \\
\text { capability }\end{array}$ & Strategic dependency \\
& & & $\begin{array}{l}\text { Supplier' financial } \\
\text { capability }\end{array}$ & Strategies \& policies \\
\hline
\end{tabular}

Due to the limited number of experts in the organization (designers, chief of staffs, project managers, managers of quality assurance and procurement experts), 30 employees assisted in collecting the required data. The questionnaire was classified according to the Likert scale and the respondents were asked to determine the compliance of each of the criteria with the requirements and the conditions of their organization; according to the investigations conducted by the academic and organizational experts, the formal and content validity of the questionnaire was examined. In this way, 10 questionnaires were submitted to 10 related specialists and after problem solving and final confirmation, they were used for data collection. To determine the reliability of the questionnaire, Cronbach's alpha method was used and SPSS statistical software was used for statistical analysis. The Cronbach's alpha value of the prepared questionnaire is 0.751 , which indicates that the reliability of the questionnaire is desirable.

\subsection{Normality test}

Kolmogorov-Smirnov test was used to study the normality of the data. In all tests, the statistical hypotheses are assumed as $\left(\mathrm{H}_{0}\right.$ : Data are normally distributed, $\mathrm{H}_{1}$ : Data are not normally distributed).

\section{Table 2}

Results of normality test

\begin{tabular}{|c|c|c|c|c|c|}
\hline Components & $\mathrm{K}-\mathrm{S}$ test & p-value & Dist. & Kind of test & Hypothesis test \\
\hline Supplier capability in crisis & 0.946 & 0.332 & Normal & Parametric & T-test \\
\hline financial capability of supplier & 1.208 & 0.108 & Normal & Parametric & T-test \\
\hline Technological capability of supplier & 1.713 & 0.006 & Non-normal & Nonparametric & Binomial \\
\hline Technical flexibility of supplier & 1.432 & 0.033 & Non-normal & Nonparametric & Binomial \\
\hline Volume flexibility of supplier & 1.533 & 0.018 & Normal & Parametric & T-test \\
\hline Sufficiency of supplier' capacity & 1.716 & 0.004 & Non-normal & Nonparametric & Binomial \\
\hline Cost saving & 1.270 & 0.080 & Normal & Parametric & T-test \\
\hline Costs of outsourcing management & 1.591 & 0.013 & Normal & Parametric & T-test \\
\hline Product architecture & 1.475 & 0.026 & Non-normal & Nonparametric & Binomial \\
\hline Technical attractiveness (candidate) & 1.118 & 0.164 & Normal & Parametric & T-test \\
\hline Financial attractiveness (candidate) & 0.928 & 0.355 & Normal & Parametric & T-test \\
\hline Sufficiency of internal capacity & 1.414 & 0.037 & Non-normal & Nonparametric & Binomial \\
\hline Organizational Learning and growth & 1.255 & 0.086 & Normal & Parametric & T-test \\
\hline Risk of technical information leakage & 1.457 & 0.029 & Normal & Parametric & T-test \\
\hline Risk of security information leakage & 1.892 & 0.002 & Non-normal & Nonparametric & Binomial \\
\hline Risk of strategic information leakage & 1.545 & 0.017 & Non-normal & Nonparametric & Binomial \\
\hline Risk of know how losing & 1.108 & 0.172 & Normal & Parametric & T-test \\
\hline Organization's weakness in fulfilling its obligations & 1.501 & 0.022 & Non-normal & Nonparametric & Binomial \\
\hline Strategies \& policies alignment & 1.542 & 0.017 & Non-normal & Nonparametric & Binomial \\
\hline Internal technological capability & 1.458 & 0.029 & Non-normal & Nonparametric & Binomial \\
\hline Deepening employees' knowledge and skills & 1.492 & 0.023 & Non-normal & Nonparametric & Binomial \\
\hline Risk of employees' commitment reducing & 1.054 & 0.217 & Normal & Parametric & T-test \\
\hline
\end{tabular}


If the significance level ( $\mathrm{p}$-value) is greater than 0.05 , null hypothesis is approved and the data has normal distribution; otherwise null hypothesis assumption is rejected and data distribution is not normal. For normal components, one-sample parametric t-test and for non-normal components nonparametric binomial test are used. The normal test results are presented in Table 2.

\subsection{One-sample parametric T-test}

This is a parametric test and is used to examine the claim of the influence of normal components on outsourcing decision making. In fact, this test accepts the claim of the influence of desired component if most respondents respond to options are above 3 (i.e. $\mathrm{H}_{0}: \mu=3, \mathrm{H}_{0}: \mu \neq 3$ ). The null hypothesis is rejected for components with a significance level below 0.05 , which means that for these components, the mean has a significant difference with the number 3 (average value) and components that have a significance level greater than 0.05 confirm the null hypothesis; that is, the mean values of these components do not have a significant difference with the mean value of 3 . Therefore, the one-sample t-test does not have any reason to accept the influence. Then, for the components that the null hypothesis is rejected, we examine the upper and lower bounds. For components with a positive lower and upper limit, an average value higher than 3 is acceptable. The results are presented in Table 3.

Table 3

One-sample T-test results

\begin{tabular}{lccccc} 
Components & p-value & $\begin{array}{c}\text { accept / } \\
\text { reject null } \\
\text { hypothesis }\end{array}$ & $\begin{array}{c}\text { Lower } \\
\text { limit }\end{array}$ & Upper limit & $\begin{array}{c}\text { accept / } \\
\text { reject claim }\end{array}$ \\
\hline Supplier capability in crisis & 0.063 & accept & -- & -- & reject \\
Financial capability of supplier & 0.005 & reject & 0.8933 & 0.1781 & accept \\
Cost saving & 0.722 & accept & -- & -- & reject \\
Technical attractiveness & 0.007 & reject & -0.1629 & -0.9086 & accept \\
Financial attractiveness & 0.174 & accept & -- & -- & reject \\
Organizational Learning and growth & 0.515 & accept & -- & -- & reject \\
Risk of know how losing & 0.002 & reject & 1.1345 & 0.2940 & accept \\
Risk of employees' commitment reducing & 1.000 & accept & -- & -- & reject \\
\hline
\end{tabular}

\subsection{Non-parametric binomial test}

This is a nonparametric test and is used to study the claim of the influence of non-normal components on outsourcing decision making. In fact, this test accepts the claim of the desired component if most respondents respond to options above 3 . Test hypotheses are $\left(\mathrm{H}_{0}: \mu=3, \mathrm{H}_{1}: \mu \neq 3\right)$.

Table 4

Binomial Test Results

\begin{tabular}{|c|c|c|c|c|c|}
\hline Components & p-value & $\begin{array}{l}\text { accept / } \\
\text { reject null } \\
\text { hypothesis }\end{array}$ & $\begin{array}{c}\text { Frequency } \\
\text { of responses } \\
3 \text { and less } \\
\text { than } 3\end{array}$ & $\begin{array}{c}\text { Frequency of } \\
\text { responses } \\
\text { more than } 3\end{array}$ & $\begin{array}{l}\text { accept } \\
\text { reject } \\
\text { claim }\end{array}$ \\
\hline Technological capability of supplier & 0.000 & reject & 1 & 27 & accept \\
\hline Technical flexibility of supplier & 0.013 & reject & 7 & 21 & accept \\
\hline Volume flexibility of supplier & 0.036 & reject & 20 & 8 & reject \\
\hline sufficiency of supplier' capacity & 0.004 & reject & 6 & 22 & accept \\
\hline costs of outsourcing management & 0.000 & reject & 26 & 2 & reject \\
\hline Risk of damage to product integration & 0.000 & reject & 3 & 25 & accept \\
\hline sufficiency of internal capacity & 0.036 & reject & 8 & 20 & accept \\
\hline Risk of technical information leakage & 0.000 & reject & 4 & 24 & accept \\
\hline Risk of security information leakage & 0.000 & reject & 3 & 25 & accept \\
\hline Risk of strategic information leakage & 0.851 & accept & - & - & reject \\
\hline Organization's weakness in fulfilling its & 0.345 & accept & - & - & reject \\
\hline Strategies \& policies alignment & 0.013 & reject & 7 & 21 & accept \\
\hline Internal technological capability & 0.572 & accept & - & - & reject \\
\hline Internal technological capability & 0.851 & accept & - & - & reject \\
\hline
\end{tabular}


The test assumption is rejected for components with a significant level below 0.05 , which means that for these components, the mean has a significant difference with the number 3 (average value).Then, for the components that the zero assumption is rejected for, the frequency of respondents to options 3 and below 3 is less, and accepted, otherwise, so we examine the average value above 3 . If the frequency of the second group is greater, the claim of the component influence is confirmed. The results are presented in Table 4. Based on the results of both tests, the variables (probability of loss of technical and managerial knowledge from outsourcing, supplier financial capabilities, supplier technological capability, supplier flexibility in technical aspects of activity, supplier capacity adequacy, internal capacity adequacy, product architecture and its integrity, risk of product technical information disclosure, risk of product safety information disclosure, consideration of organizational strategies and policies) are approved and the variables (technical attractiveness of the target activity, reduction of employee commitment and concentration, increased organizational growth and learning, and gain of experience in the organization, financial attractiveness of target activity, cost savings, supplier's ability in crisis, outsourcing management related costs, supplier flexibility in terms of activity volume, organization's technological capability in the outsourcing candidate activity, deepening of employee knowledge and skills, undermining the organization in practice of its obligations due to supplier dependency, risk of exposing organization's strategic plans) are rejected.

\section{The decision-making framework}

The proposed framework for decision-making according to Fig. 1 is based on the following five steps. Each of the steps in the proposed framework is described below:

- Considering the candidate activity (process)

- Calculating Weights of Capacity, Technology, Strategy and financial, and Risk (CTSR) criteria

- Implementing the PROMETHEE Technique

- Performing BWG analysis

- Taking Final decision

In the first step, the activity or process that is required to decide how perform (in house or outsource) is selected as the candidate activity; in the second step, based on the pair comparison, we try to determine the weights of the ten criteria based on the CTSR dimensions. With the implementation of PROMETHEE method, the final results are derived from the software (Visual PROMETHEE), and BWG analysis can be performed based on these data, and ultimately, the final decision on outsourcing or performing in house is adopted.

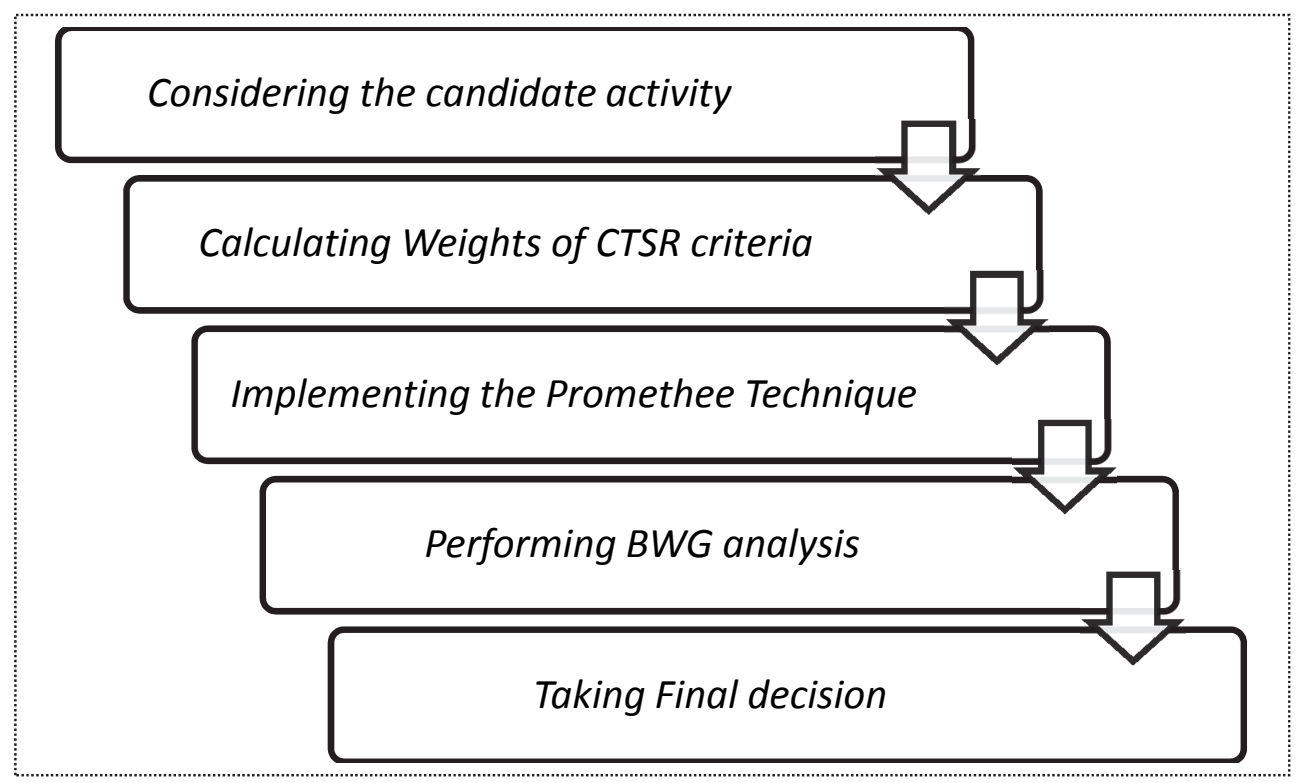

Fig. 1. The decision-making framework 


\subsection{CTSR dimensions}

After the final analysis of the test results, ten criteria have been verified which can be categorized into four categories (dimensions): Capacity, Technology, Strategy and financial, and Risk that we call CTSR as abbreviate to these four dimensions. Fig. 2 shows the CTSR dimensions and criteria related to each dimension.

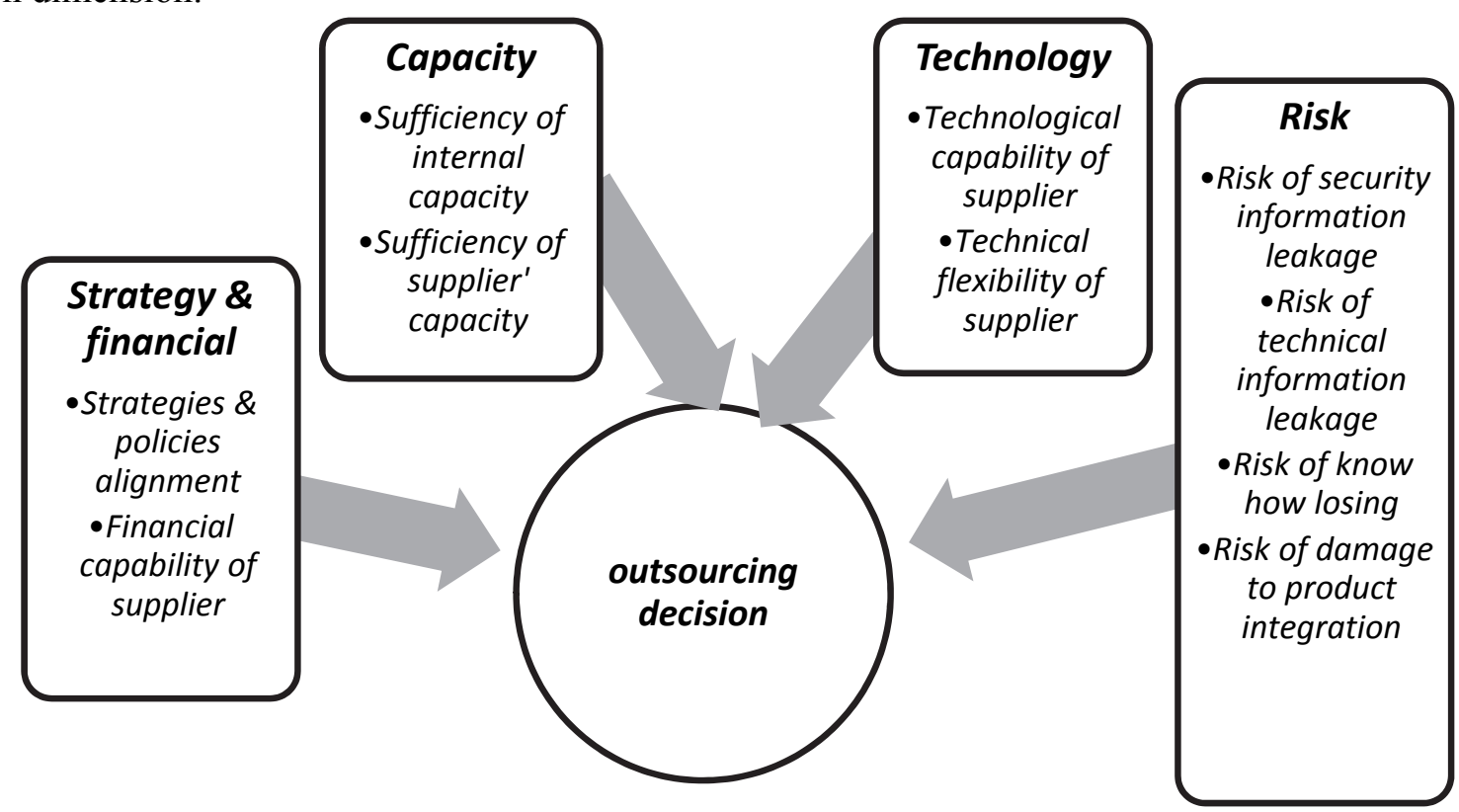

\subsection{PROMETHEE method}

Fig. 2. CTSR dimentions

The PROMETHEE method is considered as an efficient method and uses two words of preference and indifference to choose the best option. This technique was presented by two Belgian professors in the 1980s. After that, the PROMETHEE method was developed, and various versions were created in which they could be called the PROMETHEE family. PROMETHEE I lists the options in detail. PROMETHEE II categorizes discrete options in full. PROMETHEE III defines preference and nonpreference relationships based on the average and standard deviation of the preference indexes. The steps of the PROMETHEE method include the formation of an evaluation table, the calculation of the assignment function, the determination of the type of the preference function, the calculation of the total preference function and the calculation of positive and negative flows, respectively. The positive flow, is the dominance score of an option on other options and the negative flow, is the rate of defeat of an option versus other options. Thus, the net and final score is calculated for one option, and the option with the most positive final score is the first priority, and other options are also prioritized in this way (Halouani, et al., 2009).

\subsection{BWG analysis 1}

Based on verified criteria, PROMETHEE decision-making method, it has been attempted to determine the best option. After performing PROMETHEE calculations, it will be necessary to perform final analysis on the activity (process). Based on the first letters of black, white and gray, we call this analysis BWG analysis. This analysis will be as follows:

- Black activity: An activity where the value of $\varphi$ related to insourcing is positive and close to one, and the appropriate decision about this activity is to keep that activity within the organization.

${ }^{1}$. Black-White- Grey 
- White Activity: An activity where the value of $\varphi$ related to outsourcing is positive and close to one, and the appropriate decision on this activity is the recommendation of outsourcing.

- Gray Activity: Whatever the absolute value of $\varphi$ of each option is closer to one, the decision on them is more definitive. The closer to zero, the more the decision is relative and the closer to the indifference; therefore, given the low score of the options and the difference of absolute value from one, the decision on the desired activity is subject to knowledge and more research by experts and managers of the organization. Table 5 shows BWG analysis.

Table 5

BWG analysis

\begin{tabular}{lllll}
\hline$\varphi$ & $\varphi_{\text {insourcing }} \rightarrow 1$ & $\varphi_{\text {outsourcing }} \rightarrow 1$ & $|\varphi|$ is far from 1 \\
\hline Label & Black & & White & Grey \\
Decision & Insourcing & Outsourcing & expertise/ contingency \\
\hline
\end{tabular}

\subsection{Paired comparisons and determining weights of criteria}

Since the criteria do not have the same effect, using "Expert Choice" software, all the questionnaires were entered and the calculations were carried out. The description of the chart and the rate of inconsistency in the graph is specified to express the impact of each criterion using the pair comparison, and the results are shown in Table 5.

\section{Table 5}

Weights of decision aiding criteria

\begin{tabular}{ll}
\hline Criteria & Weight \\
\hline Technological capability of supplier & 0.222 \\
Risk of security information leakage & 0.176 \\
Risk of technical information leakage & 0.140 \\
Risk of damage to product integration & 0.115 \\
Sufficiency of supplier' capacity & 0.036 \\
Strategies \& policies alignment & 0.031 \\
Sufficiency of internal capacity & 0.016 \\
Risk of know how losing & 0.013 \\
Financial capability of supplier & 0.011 \\
Technical flexibility of supplier & 0.043 \\
\hline
\end{tabular}

We decide individually for each activity, and we consider the decision options, i.e. insourcing and outsourcing. For this purpose, another questionnaire was designed and provided to industry experts in which, for each activity, the weight of each option (outsourcing or insourcing) was measured according to the criteria, and eventually with the "Visual PROMETHEE" software, the options were ranked according to the scores respectively. The results of BWG analysis are as follows:

Black Activity: The decision options score is presented in Fig. 3. Given the fact that insourcing is positive, and also the close proximity of this scores to one, managers of case study can perform the black activity internally.

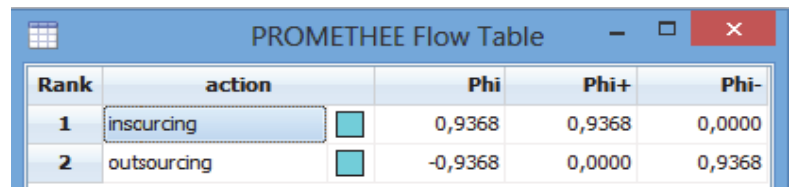

Fig. 3. $\varphi$ for decision options of black activity

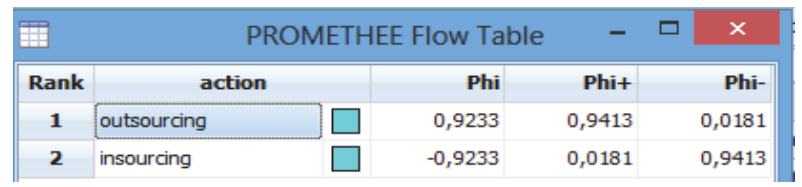

Fig. 4. $\varphi$ for decision options of white activity

White Activity: The decision options score is listed in Fig. 4. Given the fact that the outsourcing is positive, and also the closeness of this score to one, white activity can be outsourced.

Gray Activity: The decision options score is shown in Fig. 5. Due to the positive insourcing, this option is recommended for this activity but given its low $\varphi$, the decision taking is based on the opinion of the organization's experts. 


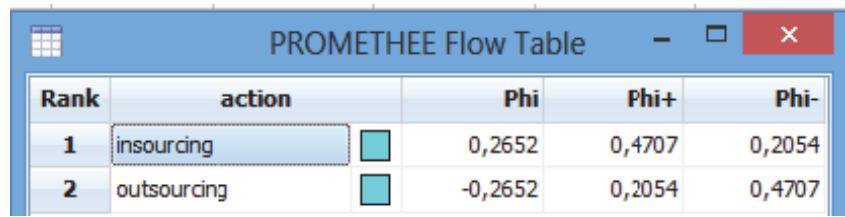

\section{Conclusion}

Fig. 5. $\varphi$ for decision options of gray activity

The framework presented in this article is useful for outsourcing decision makers and managers; however, due to the importance of the outsourcing decisions, the development of current research and the pursuit of similar research in order to richen the subject matter is always critical. Another important point in the development of outsourcing approaches and decision models includes attention to the limitations of this area; for decision makers in this area, information constraints, the need for simple tools, and the use of appropriate software, attention to conceptual richness and creation of effective and robust frameworks for decision making, and ultimately the possibility of easy and straightforward interpretation of the results achieved in reaching the final decision will be important.

\section{References}

Agrawal, S., Singh, R. K., \& Murtaza, Q. (2016). Outsourcing decisions in reverse logistics: sustainable balanced scorecard and graph theoretic approach. Resources, Conservation and Recycling, 108, 41-53.

Aikhuele, D., \& Turan, F. (2017). A subjective and objective fuzzy-based analytical hierarchy process model for prioritization of lean product development practices. Management Science Letters, 7(6), 297-310.

Attari, M. Y. N., Bagheri, M., \& Jami, E. N. (2012). A decision making model for outsourcing of manufacturing activities by ANP and DEMATEL under fuzzy environment. International Journal of Industrial Engineering, 23(3), 163-174.

Aubert, B. A., Rivard, S., \& Patry, M. (2004). A transaction cost model of IT outsourcing. Information \& management, 41(7), 921-932.

Bageri, M. R. (2008). A decision making model for outsourcing production activities under uncertainty. Islamic Azad University, Najaf Abad Branch: Master thesis.

Ball, D. (2003). A weighted decision matrix for outsourcing library services. The Bottom Line: Managing Library Finances .

Bertolini, M., Bevilacqua, M., Braglia, M., \& Frosolini, M. (2004). An analytical method for maintenance outsourcing service selection. International Journal of Quality \& Reliability Management, 21(7), 772-788.

Bustamante, C. V. (2018). Strategic choices: Accelerated startups' outsourcing decisions. Journal of Business Research, https://doi.org/10.1016/j.jbusres.2018.06.009

Cánez, L. E., Platts, K. W., \& Probert, D. R. (2000). Developing a framework for make-or-buy decisions. International Journal of Operations \& Production Management, 20(11), 1313-1330.

Chang, S. I., Yen, D. C., Ng, C. S. P., \& Chang, W. T. (2012). An analysis of IT/IS outsourcing provider selection for small-and medium-sized enterprises in Taiwan. Information \& Management, 49(5), 199-209.

Cheshmberah, M., \& Mortazavi, S. M. (2009). Outsourcing effectiveness management. Tehran: Mehrban Publication (In Persian).

Cheshmberah, M., Makui, A., \& Seyedhoseini, S. (2011a). A new fuzzy MCDA framework for make-or-buy decisions: A case study of aerospace industry. Management Science Letters, 1(3), 323-330.

Cheshmberah, M., Makui, A., Seyedhoseini, S. M., \& Yousefi, S. (2011b). Analysing the impact of the product life cycle on the importance of outsourcing decision-making criteria: A manufacturing case study. South African Journal of Industrial Engineering, 22(2), 216-226.

Cheshmberah, M., \& Nabavi, S. (2014). An application of Six Sigma DMAIC methodology in outsourcing management process improvement. Uncertain Supply Chain Management, 2(3), 115-124.

Fill, C., \& Visser, E. (2000). The outsourcing dilemma: a composite approach to the make or buy decision. Management decision, 38(1), 43-50.

Fine, C. H., Vardan, R., Pethick, R., \& El-Hout, J. (2001). Moving a slowclockspeed business into the fast lane: strategic sourcing lessons from value chain redesign in the automotive industry. Sloan Management Review, July 2001. 
Georgantzas, N. C. (2001). Virtual enterprise networks: the fifth element of corporate governance. Human Systems Management, 20(3), 171-188.

Halouani, N., Chabchoub, H., \& Martel, J. M. (2009). PROMETHEE-MD-2T method for project selection. European Journal of Operational Research, 195(3), 841-849.

Hessami, F. (2018). Business risk evaluation and management of Iranian commercial insurance companies. Management Science Letters, 8(2), 91-102.

Al-Kahtani, N. (2018). The impact of demographical variables on HRM practices in Saudi Telecom Company: An empirical exploration. Management Science Letters, 8(3), 131-138.

Milecová, M., Grznar, M., \& Szabo, L. (2010). Outsourcing: Decision making in the case of outsourcing the company activity and the management of outsourcing project. Agricultural Economics Journal, 56(8), 387396.

Miltenburg, P. R. (2003). Effects of modular sourcing on manufacturing flexibility in the automotive industry. A study among German OEMs (No. ERIM PhD Series; EPS-2003-030-ORG).

Modaka, M., Ghosha, K. K., \& Pathak, K. (2018). A BSC-ANP approach to organizational outsourcing decision support-A case study. Journal of Business Research.https://doi.org/10.1016/j.jbusres.2018.01.040

Modak, M., Pathak, K., \& Ghosh, K. K. (2017). Performance evaluation of outsourcing decision using a BSC and Fuzzy AHP approach: A case of the Indian coal mining organization. Resources Policy, 52, 181-191.

Motadel, M. R., Afshar Kazemi, M. A., \& Dastbaz, S. (2011). A model for supporting decisions on outsourcing IT projects using a group decision method. Management Projects, (In Persian).

Nakhaee, E., \& Bageri, M. R. (2008). a decision-making model for outsourcing production activities using ANP and DEMATEL techniques in fuzzy environment. Industrial Management Magazine (Islamic Azad University of Sanandaj).

Nayak, J. K., Sinha, G., \& Guin, K. K. (2007). The determinants and impact of outsourcing on small and medium enterprises-an empirical study. IIMB Management Review, 19(3), 277-284.

Niemira, M. P., \& Saaty, T. L. (2004). An analytic network process model for financial-crisis forecasting. International Journal of Forecasting, 20(4), 573-587.

Padillo, J. M., \& Diaby, M. (1999). A multiple-criteria decision methodology for the make-or-buy problem. International Journal of Production Research, 37(14), 3203-3229.

Prahalad, C. K., \& Hamel, G. (1993). The core competence of the corporation, Harvard Business School Pub. Corp., Boston, MA.

Probert, D. R. (1996). The practical development of a make or buy strategy: the issue of process positioning. Integrated Manufacturing Systems, 7(2), 44-51.

Saaty, R. W. (1987). The analytic hierarchy process - what it is and how it is used. Mathematical Modelling, 9(35), 161-176.

Sharma, A., Moon, J., Baig, J. I., Choi, J. G., Seo, K., \& Donatone, L. C. (2015). Cost-benefit framework for K12 foodservice outsourcing decisions. International Journal of Hospitality Management, 45, 69-72.

Tayles, M., \& Drury, C. (2001). Moving from make/buy to strategic sourcing: the outsource decision process. Long range planning, 34(5), 605-622.

Tjader, Y., May, J. H., Shang, J., Vargas, L. G., \& Gao, N. (2014). Firm-level outsourcing decision making: A balanced scorecard-based analytic network process model. International Journal of Production Economics, 147, 614-623.

Venkatesan, R. (1992). Strategic sourcing: To make or not to make. Harvard Business Review, 70(6), 98-107.

Van de Water, H., \& Van Peet, H. P. (2006). A decision support model based on the analytic hierarchy process for the make or buy decision in manufacturing. Journal of Purchasing and Supply Management, 12(5), 258271.

Welch, J. A., \& Nayak, P. R. (1992). Strategic sourcing: a progressive approach to the make-or-buy decision. Academy of Management Perspectives, 6(1), 23-31.

Wu, W. W., \& Lee, Y. T. (2007). Developing global managers' competencies using the fuzzy DEMATEL method. Expert systems with applications, 32(2), 499-507.

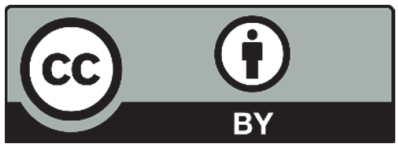

(C) 2019 by the authors; licensee Growing Science, Canada. This is an open access article distributed under the terms and conditions of the Creative Commons Attribution (CC-BY) license (http://creativecommons.org/licenses/by/4.0/). 